\title{
Local Strain Energy Density Applied to Bainitic Functionally Graded Steels Plates Under Mixed-Mode (I + II) Loading
}

\author{
H. Salavati $\cdot$ Y. Alizadeh $\cdot$ F. Berto
}

Received: 10 March 2014/Revised: 20 May 2014/Published online: 25 December 2014

(C) The Chinese Society for Metals and Springer-Verlag Berlin Heidelberg 2014

\begin{abstract}
In this paper, the averaged value of the strain energy density (SED) over a control volume is used to predict the critical load of V-notched specimens made of functionally graded steels (FGSs) under mixed-mode loading. The studied FGSs contain ferritic and austenite phases in addition to bainitic layer produced by electroslag remelting. The mechanismbased strain gradient plasticity theory is used to determine the flow stress (yield stress or ultimate stress) of each layer. The Young's modulus and the Poisson's ratio have been assumed to be constant, while other mechanical properties vary exponentially along the specimen width. The control volume is centered in relation to the maximum principal stress present on the notch edge and assumes a crescent shape. The points belonging to the volume perimeter are obtained numerically. In the present contribution, the effects of notch radius and notch depth on the SED and the critical load are studied. The notch radius varies from 0.2 to $2.0 \mathrm{~mm}$, and the notch depth varies from 5 to $7 \mathrm{~mm}$. By using the SED approach and finite element simulations, the critical load is determined, and the obtained results show a sound agreement with the experimental results.
\end{abstract}

KEY WORDS: Functionally bainitic graded steel; Strain energy density; Mechanism-based strain gradient plasticity theory; Critical load; Notch radius; Notch depth

\section{Introduction}

Notches in structural components are weak points that may generate cracks or lead to fatigue crack initiation (see among the others Refs. [1, 2]). Several criteria have been proposed to assess fracture loads of notched components subjected to mode I loading [3-7]. Recently, the fracture loads of the notched specimens (sharp and blunted $\mathrm{U}$ and $\mathrm{V}$

Available online at http://link.springer.com/journal/40195

H. Salavati · Y. Alizadeh ( $₫)$

Department of Mechanical Engineering, Amirkabir University

of Technology, Tehran, Iran

e-mail: alizadeh@aut.ac.ir; yoness.alizadeh@gmail.com

\section{F. Berto}

Department of Management and Engineering, University

of Padova, Vicenza, Italy notches) loaded under mode I have been successfully assessed, utilizing two criteria: one based on the cohesive zone model [8-11]; and the other based on the strain energy density (SED) [12-17]. A complete review of the volume-based SED approach applied to $\mathrm{V}$-notches and welded structures has been done in Ref. [18]. Under mode I loading, fracture systematically initiates at the notch along the notch bisector line; this is the point where both the principal stress and the SED reach their maximum values. On the other hand, the point where fracture initiates under mixed-mode loading varies from case to case, because it depends on the geometry of the notch and on the mode mixity. Different mode mixity values can be obtained by varying the scheme of application of the external load [19, 20]. In light of these considerations, it is then clear that the problem of brittle failure of blunted notches loaded under mixed-mode loading is more complex than the corresponding problem under mode I. Moreover, in the 
literature, there are only few experimental data for notches characterized by a non-negligible radius and subjected to mixed-mode loading [21-24]. The main advantages of the SED with respect to other criteria are that it can directly capture three-dimensional (3D) effects [25-27], and it can be calculated with high accuracy by means of coarse meshes [28, 29].

Functionally graded steels (FGSs) are innovative materials which attract strong interests from many researchers. These new materials allow for higher combinations of strength and ductility compared with traditional highstrength steels. FGSs may be produced during welding of alloy steels. Recently, FGSs have been produced by electroslag remelting (ESR) [30]. Studies on transformation characteristics of FGSs produced from austenitic stainless steel and plain carbon steel have shown that as chromium, nickel, and carbon atoms diffuse at the remelting stage, alternating regions with different transformation characteristics can be created in the material. By selecting appropriate arrangement and thickness of original electrodes made of ferritic and austenitic steels, composites with graded ferritic $(\alpha)$ and austenitic $(\gamma)$ regions together with bainitic $(\beta)$ or martensitic (M) layers can be obtained [31].

In some previous studies, FGSs with different configurations were produced, and the tensile behavior was experimentally investigated and modeled [31]. Recently, Vickers microhardness profile of the $\alpha / \beta / \gamma$ FGSs was assessed using the mechanism-based strain gradient plasticity (MSG) theory [32]. The main advantage of this model is that the microhardness of each layer (i.e., microhardness profile) is not required for determining the mechanical properties of the FGSs. In another study, the fracture toughnesses of ferritic and austenitic FGSs have been modeled based on the MSG theory [33]. Dealing with a crack divider configuration, the fracture toughness of the FGSs has been evaluated using the area under the stressstrain curve of each layer and the rule of mixtures [34]. The fracture toughness of each layer has been assessed as a function of the position of that layer. Plane stress conditions were assumed for edge layers, while plane strain conditions were presumed for central layers. Finally, a mathematical model as a function of the type of the considered composite, the volume fraction, and the position of the containing phases was presented to predict the fracture toughness. In another study [35], a development of the previous model was made to increase the accuracy in fracture toughness prediction.

In Ref. [36], a theoretical model has been proposed to assess the flow stress of FGSs under hot compression loading based on the rule of mixtures. In the cited paper, the parameters to be inserted in the constitutive equation of each layer have been determined using some empirical relationships giving the Vickers hardness profile of the considered structure.

In Ref. [37], the effect of the distance between the notch tip and the position of the median phase on the Charpy impact energy has been investigated. The results showed that when the notch apex is close to the median layer, the impact energy reaches its maximum value due to the increment of the absorbed energy by plastic deformation ahead of the notch tip. On the other hand, when the notch apex is far from the median layer, the impact energy strongly decreases.

The brittle or quasi-brittle static failure of FGSs by considering a crack arrester configuration was studied by Barati et al. [38]. The cited paper dealt with specimens made of $\gamma \mathbf{M} \gamma$ FGS weakened by U-notches.

In the present study, functionally bainitic graded steels are produced via ESR method, and the MSG theory is used to determine the flow stress (yield stress or ultimate stress) of each layer. Then, the crescent shape control volume necessary to the fracture assessment of V-notched specimens made of FGS has been obtained numerically under mixed-mode loading, and the critical load is predicted by the averaged value of the SED. Moreover, the effects of notch depth and notch radius on the SED and the critical load have been studied. Finally, the theoretical predictions are compared with the experimental results.

\section{Experimental}

The FGSs considered in the present investigation were obtained from ingots made of ferritic AISI 1020 and austenitic AISI 316L steels. The diameters of the ingots were $45 \mathrm{~mm}$. The chemical compositions of the two materials are summarized in Table 1. The initial consumable electrodes were prepared by cutting some bars and by spotwelding them together to obtain the desired FGS. A single bar of austenitic steel, with an initial length of $210 \mathrm{~mm}$, and a single bar of ferritic steel with an initial length of $150 \mathrm{~mm}$ spot-welded together were used to produce the two-piece electrode for the fabrication of bainitic specimens. The mechanical properties of single-phase steels present in the considered FGSs are summarized in Table 2.

During the fabrication process, the electrodes were welded to a steel bar and successively inserted vertically in the ESR furnace. The furnace contained a $70 \mathrm{~mm} \times 70 \mathrm{~mm}$ squared copper mold.

As the first step of the process, some slag was inserted in the starter and melted by activating the electrical power. The liquid, generated by the starter during the melting process, filled the plate cavity. Afterward, other slag was continuously added to the mold with the aim toward increasing the electrical resistance. The slag was made of 
Table 1 Chemical compositions of original ferritic and austenitic steels (wt $\%$ )

\begin{tabular}{lllllllllll}
\hline Steel & $\mathrm{C}$ & $\mathrm{Ni}$ & $\mathrm{Cr}$ & $\mathrm{Mo}$ & $\mathrm{Cu}$ & $\mathrm{Si}$ & $\mathrm{Mn}$ & $\mathrm{S}$ & $\mathrm{P}$ & $\mathrm{Fe}$ \\
\hline 316L $(\alpha)$ & 0.01 & 9.58 & 16.69 & 1.89 & 0.43 & 0.53 & 1.5 & 0.04 & 0.04 & Bal. \\
AISI1020 $(\gamma)$ & 0.11 & 0.07 & 0.12 & 0.02 & 0.29 & 0.19 & 0.63 & 0.08 & 0.01 & Bal. \\
\hline
\end{tabular}

Table 2 Mechanical properties of single phase steels present in the considered FGSs [22, 23]

\begin{tabular}{lllccc}
\hline Phase & $\begin{array}{l}\text { Yield strength } \\
(\mathrm{MPa})[22]\end{array}$ & $\begin{array}{l}\text { Ultimate strength } \\
(\mathrm{MPa})[22]\end{array}$ & $\begin{array}{l}\text { KIC } \\
{\left[\mathrm{MPa} . \mathrm{m}^{0.5}\right][23]}\end{array}$ & $\begin{array}{l}\text { Poisson's } \\
\text { ratio }\end{array}$ & $\begin{array}{l}\text { Elasticity } \\
\text { module }(\mathrm{GPa})\end{array}$ \\
\hline Ferrite & 245 & 425 & 45.72 & 0.33 & 207 \\
Austenite & 200 & 480 & 107.77 & 0.33 & 207 \\
Bainite & 1025 & 1125 & 82.08 & 0.33 & 207 \\
\hline
\end{tabular}

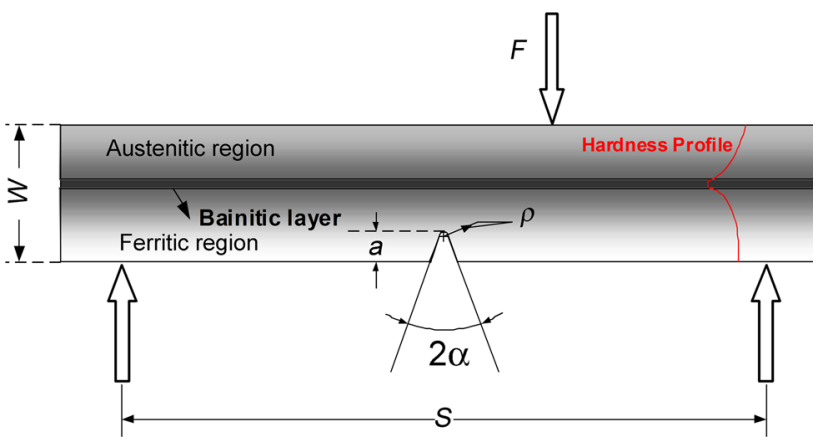

Fig. 1 Geometry of the specimen under three-point bending in the crack arrester configuration $(S=72 \mathrm{~mm}, W=18 \mathrm{~mm}, a=5.5 \mathrm{~mm}$, $\left.2 \alpha=60^{\circ}, b=5 \mathrm{~mm}\right)$

$70 \mathrm{wt} \%$ fluoride-calcium and $30 \mathrm{wt} \%$ aluminum-oxide for a total weight of $1.5 \mathrm{~kg}$.

The final ingots were of 60-mm height. By polishing and etching, a graded region in the median part of the ingots (approximately $20 \mathrm{~mm}$ high) was obtained. For metallographic examinations, the plates were sliced, ground, polished, and etched. The etching solution (Kalling) contained $5 \mathrm{~g}$ of copper-chloride, $100 \mathrm{~mL}$ of hydrochloric acid, $100 \mathrm{~mL}$ of water, and $100 \mathrm{~mL}$ of ethanol.

By means of a hot hydraulic press at $980{ }^{\circ} \mathrm{C}$, the height of the ingots was reduced to $22 \mathrm{~mm}$. The final height of $18 \mathrm{~mm}$ was obtained by grinding.

The $\alpha / \beta / \gamma$ specimens drawn from the ingots were characterized by $90 \mathrm{~mm}$ in length, $18 \mathrm{~mm}$ in width, and $9 \mathrm{~mm}$ in the thickness direction. The geometry is in agreement with the main standard in force (ASTM E1820) [39] for the crack arrester configuration.

Then, three-S point bending tests were repeated for each configuration. The load was applied normally to the interface layers during the tests with a certain distance from the notch bisector line and the point of load application $(b=5 \mathrm{~mm})$ in order to achieve a mixed-mode loading condition (Fig. 1). During each test, the notch radius and the notch opening angle were kept constant, and only the notch depth was varied. The load-displacement curves were recorded and used to obtain the critical load.

\section{Mechanism-Based Strain Gradient Plasticity (MSG) Theory}

In the present study, the flow stress (yield stress or ultimate stress) of the graded regions of the FGS has been obtained by using the MSG theory. The flow stress at each point of the graded regions of the FGS was related to the density of the statistically stored dislocations of that point by using MSG theory as follows [32]:

$\sigma_{\text {flow }(\mathrm{i})}=\sqrt{3} \alpha G b \sqrt{\left(\rho_{\mathrm{S}}^{\text {flow }}\right)_{i}}$,

where $\sigma_{\text {flow }(i)}$ indicates the flow stress (yield stress or ultimate stress) of a generic point $i$ inside the material; $G$ is the elastic shear modulus (equal to $80 \mathrm{GPa}$ for steel specimens); $\alpha$ is an empirical coefficient ranging between 0.2 and 0.5 and considered here equal to 0.3 ; and $b$ is the Burgers vector which is equal to $a_{0} \sqrt{2} / 2$ for fcc crystals (such as austenitic steels), and $a_{0} \sqrt{3} / 2$ for bcc crystals (such as ferritic steel)-wherein the parameter $a_{0}$ is the lattice parameter and is equal to $4 R / \sqrt{2}$ for fcc crystals, and $4 R / \sqrt{3}$ for bcc crystals-where $R$ is the atomic radius which is equal to $1.27 \AA$ for iron; The dislocation density around the point $i$ is indicated as $\left(\rho_{\mathrm{S}}^{\text {flow }}\right)_{i}$. The hardening mechanisms which contribute to the gradual variation of the hardness profile in a certain layer, such as the solid solution hardening and the hardening effect due to an increase of the density of the statistically stored dislocations, may be considered as a pseudo-dislocation density, $\rho_{\mathrm{S}}^{*}$ [32]. Therefore, instead of analyzing a functionally graded composite in which the strengthening effect of each element is obtained by means of the solid 


\section{(a)}

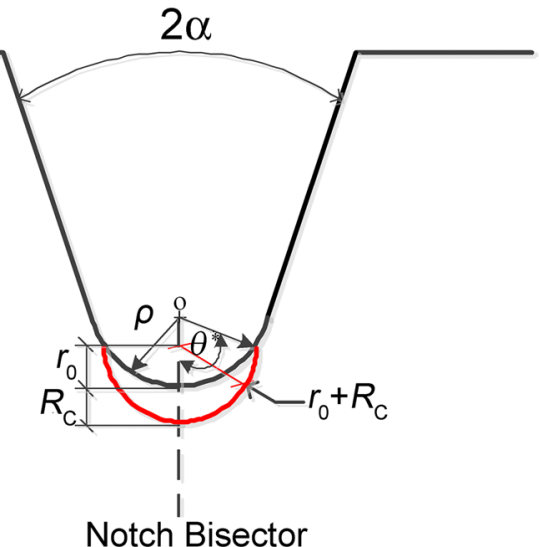

(b)

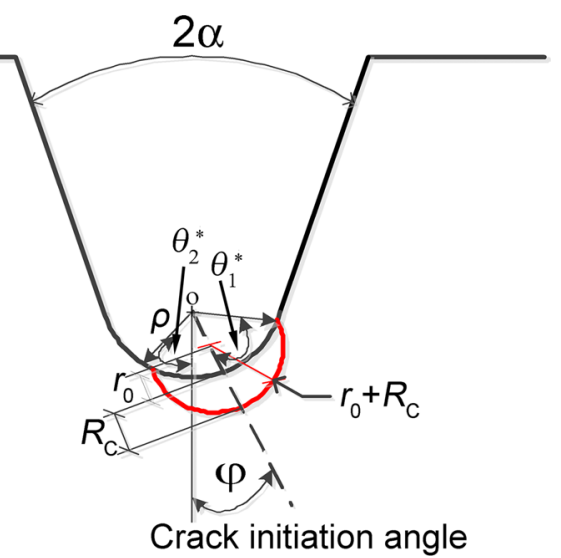

Fig. 2 Control volume for homogenous materials a mode I loading; b mixed-mode loading

(a)

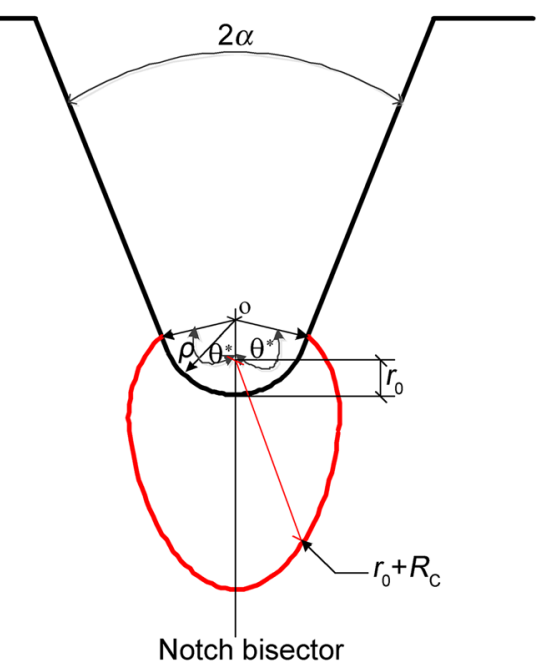

(b)

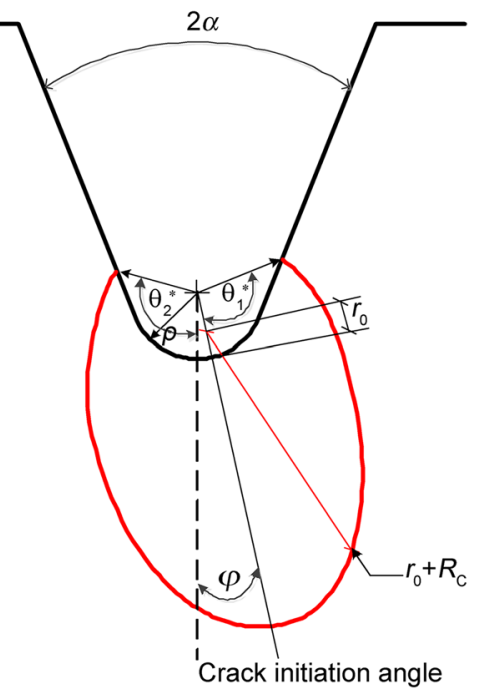

Fig. 3 Control volume for FGS materials a mode I loading; b mixed-mode loading

solution mechanism, we analyze a functionally graded composite with gradual density of dislocation having the same strengthening effect. Therefore, the flow stress of each layer is determined by the following expression:

$\sigma_{\text {flow }(i)}=\sqrt{3} \alpha G b \sqrt{\left(\rho_{\mathrm{S}}^{\text {*flow }}\right)_{i}}$,

where $\rho_{\mathrm{s}}^{* \text { flow }}$ in the graded regions has been considered to vary exponentially [32]. Therefore,

$\rho_{\mathrm{s}}^{* \text { flow }}\left(x_{i}\right)=\left(\rho_{\mathrm{s}}^{* \text { flow }}\right)_{1} e^{\left.\frac{x_{i}-x_{1}}{x_{2}-x_{1}} \cdot \ln \frac{\left(\rho_{*}^{* \text { flow }}\right)_{2}}{\left(\rho_{\mathrm{s}}^{*} \text { flow }\right.}\right)_{1}}$,

where $x_{i}$ is the position of each element in the graded regions, and $x_{1}$, and $x_{2}$ are the positions of the boundary layers. The pseudo-dislocation density for the boundary layers, $\left(\rho_{\mathrm{s}}^{* \text { flow }}\right)_{1}$ and $\left(\rho_{\mathrm{s}}^{* \text { flow }}\right)_{2}$, could be expressed as

$$
\begin{aligned}
& \left(\rho_{\mathrm{S}}^{* \text { flow }}\right)_{1}=\left[\frac{\left(\sigma_{\text {flow }}\right)_{1}}{\sqrt{3} \alpha G b}\right]^{2}, \\
& \left(\rho_{\mathrm{S}}^{* \text { flow }}\right)_{2}=\left[\frac{\left(\sigma_{\text {flow }}\right)_{2}}{\sqrt{3} \alpha G b}\right]^{2},
\end{aligned}
$$

where $\left(\sigma_{\text {flow }}\right)_{1}$ and $\left(\sigma_{\text {flow }}\right)_{2}$ are the flow stresses of the boundary layers in the graded regions.

The fracture toughness $\left(K_{\mathrm{IC}}\right)$ of the graded regions in the FGS has been also considered to vary exponentially as follows:

$K_{\mathrm{IC}}\left(x_{i}\right)=\left(K_{\mathrm{IC}}\right)_{1} e^{\frac{x_{i}-x_{1}}{x_{2}-x_{1}} \cdot \ln \frac{\left(K_{\mathrm{IC}}\right)_{2}}{\left(K_{\mathrm{IC}}\right)_{1}}}$,

where $\left(K_{\mathrm{IC}}\right)_{1}$ and $\left(K_{\mathrm{IC}}\right)_{2}$ are the fracture toughness values for the boundary layers. 


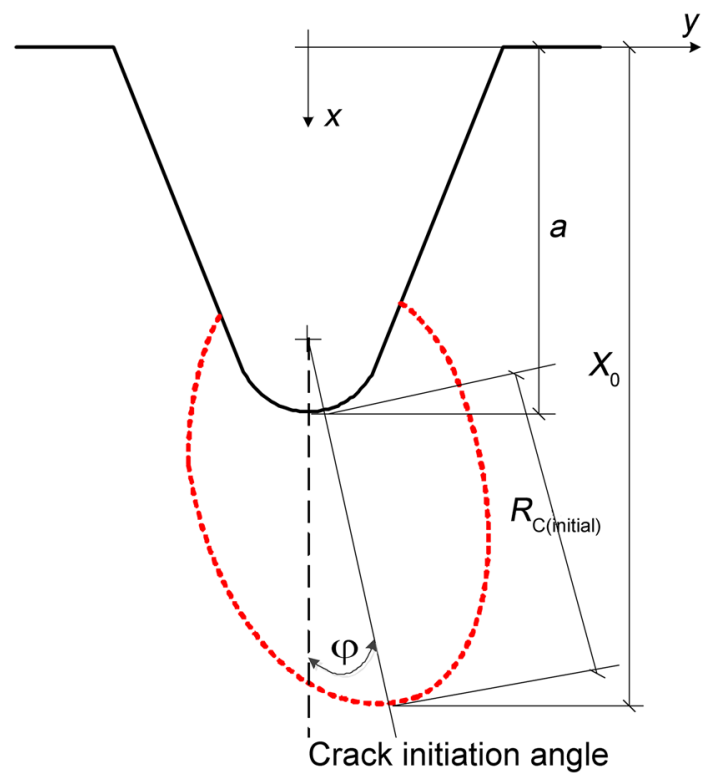

Fig. 4 Notch depth and $x-y$ Cartesian coordinate systems $\left(x_{0}\right.$ is the coordinate of the point that crack initiation occurs)

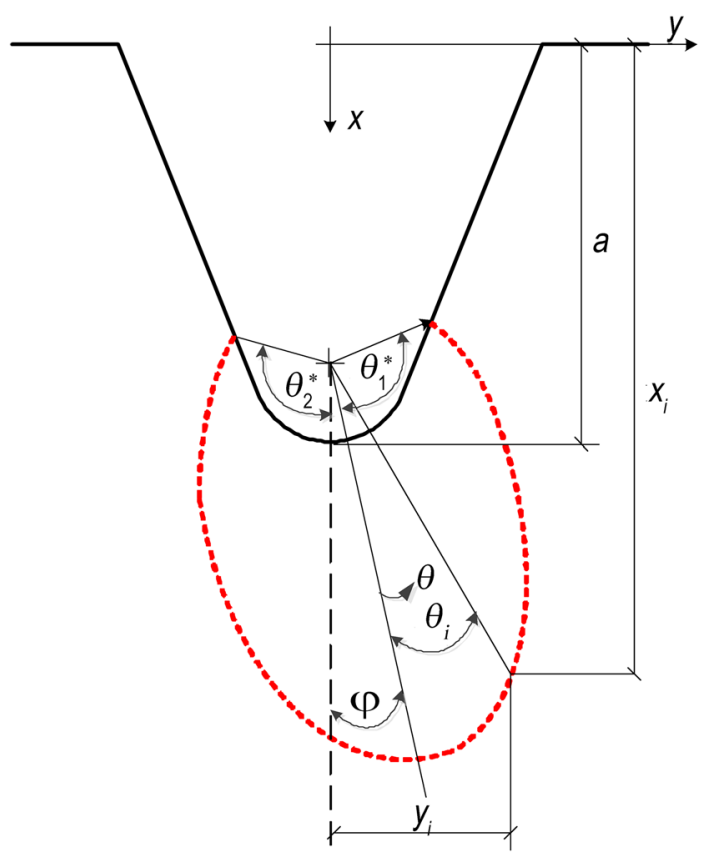

Fig. 5 Discretization of the control volume boundary

\section{Control Volume}

Under plane strain conditions, Yosibash et al. [40] evaluated the control radius $\left(R_{\mathrm{C}}\right)$ for brittle and quasi-brittle materials as a function of fracture toughness $\left(K_{\mathrm{IC}}\right)$, ultimate tensile strength $\left(\sigma_{\mathrm{ut}}\right)$, and Poisson's ratio $(v)$ of the material providing the following expression:
$R_{\mathrm{C}}=\frac{(1+v)(5-8 v)}{4 \pi}\left(\frac{K_{\mathrm{IC}}}{\sigma_{\mathrm{ut}}}\right)^{2}$.

In homogeneous materials, $R_{\mathrm{C}}$ is constant. The control volume in V-notched specimens under mode I loading conditions is centered in relation to the notch bisector line (Fig. 2a). Under mixed-mode loading, the critical volume is no longer centered on the notch tip, but rather on the point where the principal stress reaches its maximum value along the edge of the notch (Fig. 2b) [12, 19, 20].

However, in nonhomogeneous materials, $R_{\mathrm{C}}$ varies from point to point because of the material gradient. In a nonhomogeneous medium with a smooth unidirectional variation in mechanical properties in the $\mathrm{x}$-direction (along the notch depth), the outer boundary of the control volume assumes the elliptic boundary shape shown schematically in Fig. 3a (for mode I loading) and Fig. 3b (for mixed-mode loading).

In the present study, the boundary of control volume has been obtained numerically. In the numerical approach, first, the initial- $R_{\mathrm{C}}$ (control radius at the crack initiation point) has to be evaluated. $K_{\mathrm{IC}}$ and $\sigma_{\mathrm{ut}}$ vary from point to point. $\sigma_{\mathrm{ut}}\left(x_{\mathrm{i}}\right)$, the ultimate tensile strength of each layer, is obtained from Eq. (2) and $K_{\mathrm{IC}}\left(x_{\mathrm{i}}\right)$, and the fracture toughness of each layer is obtained from Eq. (5). Therefore, the following equations should be numerically solved to obtain $x_{0}$ (see Fig. 4):

$x_{0}-(a-\rho$

$$
\begin{aligned}
& +\rho \cos \varphi) \\
= & \frac{(1+v)(5-8 v)}{4 \pi}\left(\frac{K_{\mathrm{IC}}\left(x_{0}\right)}{\sigma_{\mathrm{ut}}\left(x_{0}\right)}\right)^{2} \cos \varphi .
\end{aligned}
$$

Then, the initial- $R_{\mathrm{C}}$ can be calculated as

$R_{\mathrm{C}}($ initial $)=\frac{x_{0}-(a-\rho+\rho \cos \varphi)}{\cos \varphi}$.

$R_{\mathrm{C}}$ (TE: Check subscript) (initial), for the case $\rho=2 \mathrm{~mm}, a=6.5 \mathrm{~mm}, 2 \alpha=60^{\circ}$, and $b=12 \mathrm{~mm}$, is

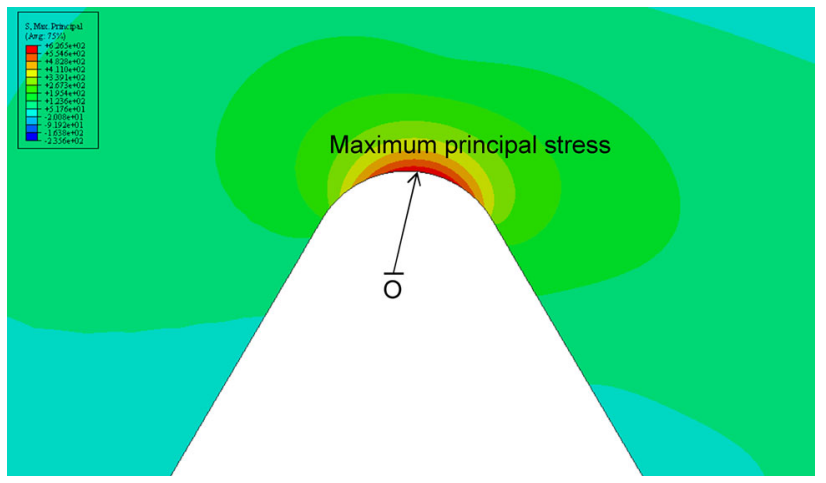

Fig. 6 Principal stress contour lines for the case $\rho=2 \mathrm{~mm}$, $a=6.5 \mathrm{~mm}, 2 \alpha=60^{\circ}, b=12 \mathrm{~mm}$ 


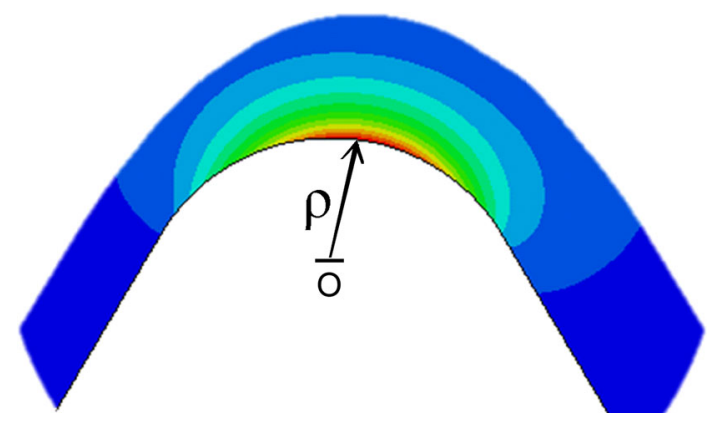

Fig. 7 SED contour lines in the control volume for the case $\rho=2 \mathrm{~mm}, \quad a=6.5 \mathrm{~mm}, \quad 2 \alpha=60^{\circ}, \quad b=12 \mathrm{~mm}\left(r_{0}+R_{\mathrm{C}}\left(x_{i}\right)=\right.$ $\left.r_{0}+\frac{(1+v)(5-8 v)}{4 \pi}\left(\frac{K_{\mathrm{IC}}\left(x_{i}\right)}{\sigma_{\mathrm{ut}}\left(x_{i}\right)}\right)^{2}\right)$

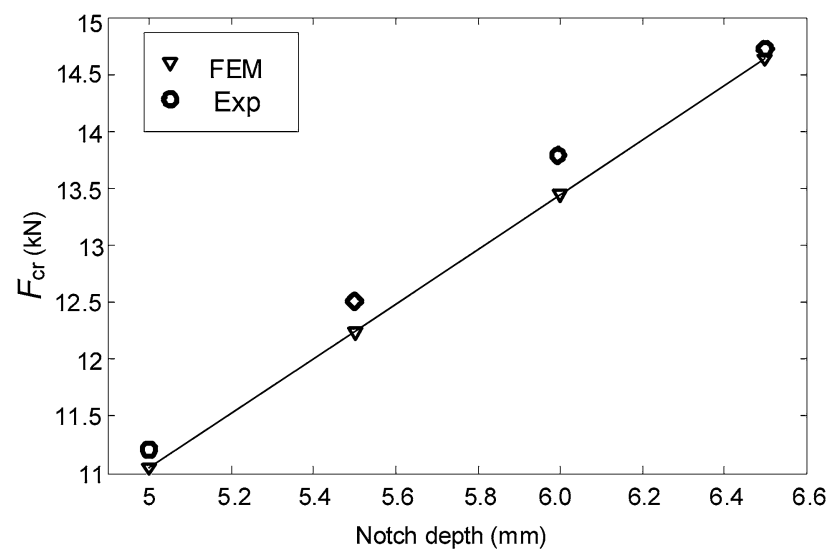

Fig. 8 Comparison between the FEM and experimental values of the critical load for different notch depths and a constant notch radius $\rho=1 \mathrm{~mm}$

equal to $1.329 \mathrm{~mm}$. In homogenous steels, the angles $\theta^{*}$ (see Fig. 3a, b) can be obtained analytically [12]. In nonhomogeneous steels, there are no analytic equations which allow for the direct determination of the angle $\theta^{*}$. Therefore, in numerical simulations, the angle $\theta^{*}$ has been varied with a constant step from zero until the control volume boundary intersects the edge of the notch. In the present study, the outer boundary of the control volume is divided into $n 1+1$ points, where $n 1$ is the integer part of the angle $\theta 1 * ; n 2+1$ points, where $n 2$ is the integer part of the angle $\theta 2 *$; and $n 3+1$ points, where $n 3$ is the integer part of the angle $\theta 3 *$ (see Fig. 5).
Table 4 SED and critical load in V-notched $\alpha \beta \gamma$ FGS for different notch radii and the constant notch depth under mixed-mode loading $\left(a=5.5 \mathrm{~mm} ; F_{\text {app }}=5 \mathrm{kN} ; \sigma_{\mathrm{UT}}=639.66 \mathrm{MPa} ; E=207 \mathrm{GPa}\right)$

\begin{tabular}{llll}
\hline$\rho(\mathrm{mm})$ & Wcr $\left(\mathrm{MJ} / \mathrm{m}^{3}\right)$ & $W_{\text {FEM }}\left(\mathrm{MJ} / \mathrm{m}^{3}\right)$ & $\begin{array}{l}\text { Critical load } \\
(\text { FEM })(\mathrm{kN})\end{array}$ \\
\hline 0.2 & 0.99 & 0.1651 & 12.24 \\
0.4 & 0.99 & 0.1635 & 12.29 \\
0.6 & 0.99 & 0.1619 & 12.35 \\
0.8 & 0.99 & 0.1604 & 12.41 \\
1 & 0.99 & 0.1588 & 12.47 \\
1.2 & 0.99 & 0.1573 & 12.53 \\
1.4 & 0.99 & 0.1558 & 12.59 \\
1.6 & 0.99 & 0.1545 & 12.64 \\
1.8 & 0.99 & 0.1534 & 12.69 \\
2 & 0.99 & 0.1524 & 12.73 \\
\hline
\end{tabular}

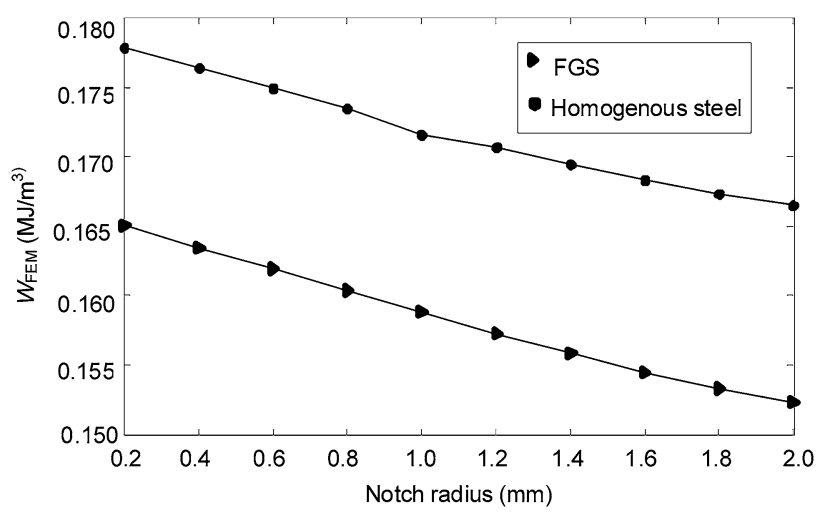

Fig. 9 Variation of the strain energy density versus the notch radius for a constant notch depth $a=5.5 \mathrm{~mm}\left(\mathrm{~F}_{\mathrm{app}}=5 \mathrm{kN}\right)$

Therefore, $x$ and $y$ coordinates of each point can be calculated by the following procedure in the $x-y$ coordinate system:

For $0<\theta<\theta 1^{*}$

$x_{i}=a-\rho+\left(R_{C}\left(x_{i}\right)+r_{0}\right) \cos (\theta+\varphi)+\left(\rho-r_{0}\right) \cos (\varphi)$.

$y_{i}=\left(R_{C}\left(x_{i}\right)+r_{0}\right) \sin (\varphi+i)+\left(\rho-r_{0}\right) \sin (\varphi)$.

For $0<\theta<\varphi$

Table 3 SED and critical load in V-notched $\alpha / \beta / \gamma$ FGS for different notch depths and the constant notch radius under mixed-mode loading $\left(\rho=2 \mathrm{~mm} ; F_{\text {app }}=5 \mathrm{kN} ; E=207 \mathrm{GPa}\right)$

\begin{tabular}{|c|c|c|c|c|c|c|}
\hline $\mathrm{a}(\mathrm{mm})$ & $\sigma_{\mathrm{UT}}(\mathrm{MPa})$ & $W_{\mathrm{cr}}\left(\mathrm{MJ} / \mathrm{m}^{3}\right)$ & $W_{\mathrm{FEM}}\left(\mathrm{MJ} / \mathrm{m}^{3}\right)$ & $\begin{array}{l}\text { Critical load } \\
(\mathrm{FEM})(\mathrm{kN})\end{array}$ & $\begin{array}{l}\text { Critical load } \\
(\operatorname{Exp})(\mathrm{kN})\end{array}$ & Error $(\%)$ \\
\hline 5 & 526.5 & 0.67 & 0.1371 & 11.05 & 11.2 & 1.3 \\
\hline 5.5 & 639.66 & 0.988 & 0.1651 & 12.24 & 12.5 & 2.1 \\
\hline 6 & 777.14 & 1.459 & 0.2017 & 13.45 & 13.8 & 2.5 \\
\hline 6.5 & 944.18 & 2.153 & 0.2511 & 14.64 & 14.7 & 0.4 \\
\hline
\end{tabular}




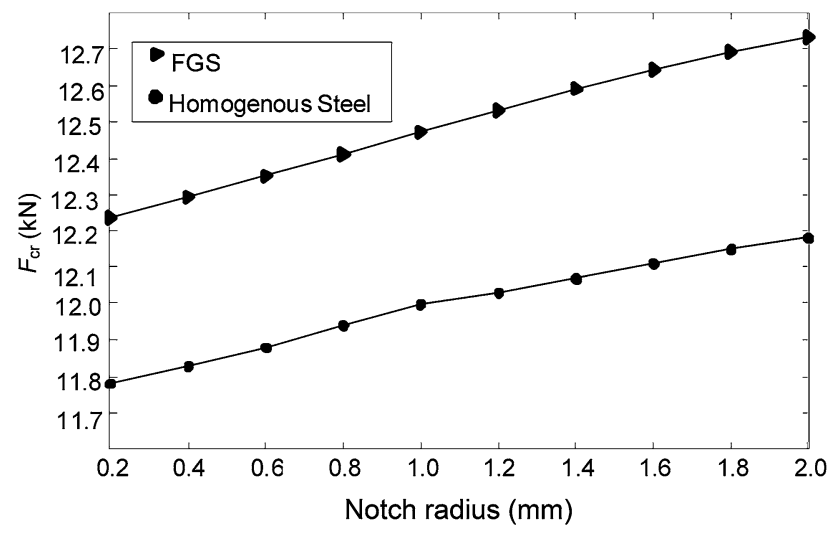

Fig. 10 Variation of the critical load versus the notch radius for a constant notch depth $a=5.5 \mathrm{~mm}$

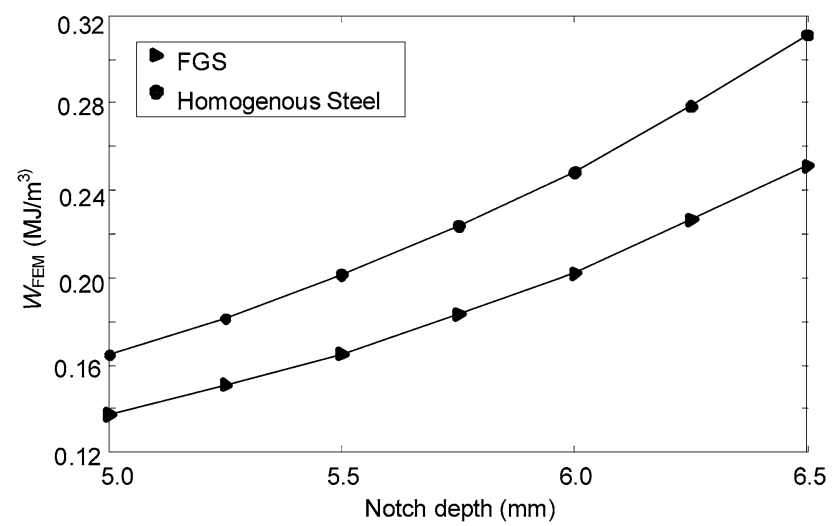

Fig. 11 Variation of the strain energy density versus the notch depth for a constant notch radius $\rho=1 \mathrm{~mm}\left(\mathrm{~F}_{\text {app }}=5 \mathrm{kN}\right)$

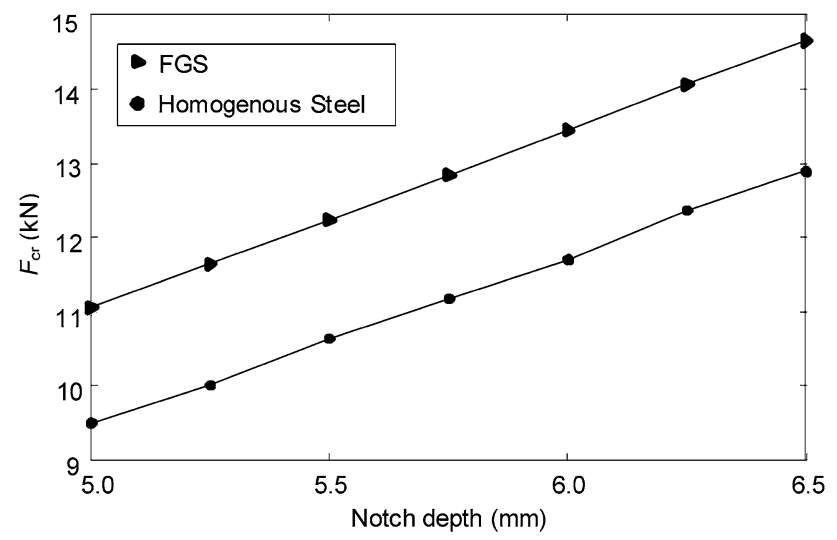

Fig. 12 Variation of the critical load versus the notch depth for a constant notch radius $\rho=1 \mathrm{~mm}$

$x_{i}=a-\rho+\left(R_{C}\left(x_{i}\right)+r_{0}\right) \cos (\varphi-\theta)+\left(\rho-r_{0}\right) \cos (\varphi)$.

$y_{i}=\left(R_{C}\left(x_{i}\right)+r_{0}\right) \sin (\varphi-i)+\left(\rho-r_{0}\right) \sin (\varphi)$.
For $\varphi<\theta<\theta 2^{*}+\varphi$

$x_{i}=a-\rho+\left(R_{C}\left(x_{i}\right)+r_{0}\right) \cos (-\varphi+\theta)+\left(\rho-r_{0}\right) \cos (\varphi)$.

$y_{i}=-\left(R_{C}\left(x_{i}\right)+r_{0}\right) \sin (i)+\left(\rho-r_{0}\right) \sin (\varphi)$.

where $R_{\mathrm{c}}\left(x_{i}\right)$ is calculated as follows:

$R_{\mathrm{C}}\left(x_{i}\right)=\frac{(1+v)(5-8 v)}{4 \pi}\left(\frac{K_{\mathrm{IC}}\left(x_{i}\right)}{\sigma_{\mathrm{ut}}\left(x_{i}\right)}\right)^{2}$,

where subscript $i$ is related to the $i$ th layer in the graded region.

\section{Critical Load}

In the present study, the averaged value of the SED over the control volume is applied to predict the critical load of the V-notched specimen under mixed-mode loading as follows:

$\frac{F_{\text {app }}}{F_{\mathrm{c}}}=\sqrt{\frac{\bar{W}_{\text {app }}}{W_{\mathrm{c}}}}$

where $F_{\text {app }}$ is the applied load, $\bar{W}_{\text {app }}$ is the averaged SED over the control volume related to the $F_{\text {app }}, F_{\mathrm{c}}$ is the critical load, and $W_{\mathrm{c}}$ is the critical SEDs which have been obtained as follows:

$W_{\mathrm{c}}=\frac{\sigma_{\mathrm{ut}}^{2}}{2 E}$.

In Eq. (14), $\sigma_{\mathrm{ut}}$ is the ultimate tensile strength of each layer (Eq. (2)), and $E$ is the Young's modulus. We must emphasize that the Young's modulus $(E=210 \mathrm{GPa})$ and the Poisson's ratio $(v=0.33)$ have been assumed to be constant along the specimen width. In this research, finite element method (FEM) has been utilized to obtain the SED.

The maximum stress occurring along the edge of V-notch as well as the averaged SED has been calculated numerically by means of ABAQUS 6.11. For each geometry, two models were created: the first was mainly oriented to the determination of the point where the maximum principal stress was located; the second model was more refined, with an accurate definition of the control volume where the SED was averaged. All the analyses have been carried out by means of eight-node elements under plane strain conditions and linear-elastic hypotheses. The applied loads were equal to $5 \mathrm{kN}$ in all the cases. Figures 6 and 7 show the maximum principal stress and the SED contour lines inside the control volume. The SED has been found to be approximately symmetric in relation to the ideal line normal to the edge and crossing the point of the maximum principal stress.

Figure 8 shows the comparison between the FE analyses and the experimental values of the critical load for different notch depths and a constant notch radius under mixed-mode 
loading. All the notch depths were considered in the transition region from original ferrite to median bainite layer $(\alpha / \beta$ graded region) of the $\alpha / \beta / \gamma / \mathrm{FGS}$. As this figure shows, there is a good agreement between the obtained critical loads and the experimental ones for different notch depths. The main results of the FE analyses as well as the experimental ones are reported in Table 3. As this table shows, the SED and its critical value as well as the critical load increase with the increasing of the notch depth. This is due to the fact that when the notch depth increases in the $\alpha / \beta$-graded region, the ultimate strength, fracture toughness, and the absorbed energy by plastic deformation ahead of the notch tip increase.

The effects of notch radius on the SED and critical load with the constant notch depth have been obtained, and the results are summarized in Table 4. As this table shows, the critical load increases with the decreasing notch radius, while the SED decreases with the increasing notch radius. In this case, since the notch depth is constant, the ultimate strength and fracture toughness would remain constant, and the critical SED does not vary.

The SEDs of the FGSs has been compared to those evaluated in a specimen made of the same homogeneous material corresponding to the layer including the notch tip in the FGSs. The results have been obtained for different notch depths and notch radii in the $\alpha \beta$-graded region and are shown in Figs. 9 and 10. Figure 9 shows that the SED, evaluated for the same applied load $(F=5 \mathrm{kN})$, decreases with the increasing notch radius, keeping the notch depths both for the FGS and the homogeneous material constant. Figure 10 shows that the critical load increases when the notch radius increases, with the notch depth kept constant: $a=5.5 \mathrm{~mm}$. This is true for both the FGSs and the homogeneous materials.

Moreover, it can be observed that for each notch radius and a constant notch depth, the SED of the FGS is lower than that measured in the homogeneous material. On the contrary, the critical load is higher for the FG steel than it is for the homogeneous material. Figures 11 and 12 show the SED (for $F=5 \mathrm{kN}$ ) and the critical load values for the FGS and the homogeneous material by increasing the notch depth with the value of the notch radius kept constant $(\rho=1 \mathrm{~mm})$. For each value of the notch depth, keeping the notch radius constant, the SED of the FGS is lower than that evaluated in the homogeneous material. On the other hand, the critical load is higher for the FG steel than for the corresponding homogeneous material.

\section{Conclusions}

In the present study, the averaged value of the SED over a control volume is used to predict the critical load of V-notched specimens made of FGSs under mixed-mode loading. The main findings of the present study can be summarised as follows:

(1) The ultimate stress of each layer of $\alpha / \beta / \gamma$ FGS has been obtained utilizing the MSG theory, while the fracture toughness has been considered to vary exponentially along the specimen width.

(2) The control volume originally proposed for homogeneous materials has been extended here to FGS under mixed-mode loadings. The boundary of the considered control volume has been determined numerically.

(3) The average deviation between the theoretical values of the critical load and the experimental results evaluated for different notch depths and a constant notch radius is almost $1.35 \%$.

(4) The results showed that the critical load of the V-notched FGS material is higher than that of the homogeneous material placed in the region including the notch tip. The increment in terms of static strength is about $15.17 \%$ considering the case of a constant notch depth, and about $4.15 \%$ when the notch radius is kept constant.

\section{References}

[1] C. Heinze, T. Michael, A. Pittner, M. Rethmeier, Acta. Metall. Sin. (Engl. Lett.) 27, 140 (2014)

[2] Y. Sun, X. Li, X. Yu, D. Ge, J. Chen, J. Chen, Acta. Metall. Sin. (Engl. Lett.) 27, 101 (2014)

[3] M.E. Kipp, G.C. Sih, Int. J. Solids Struct. 11, 53 (1975)

[4] Z. Knésl, Int. J. Fract. R 48, 79 (1991)

[5] J.K. Knowles, E. Sternberg, Arch. Ration. Mech. Anal. 44, 187 (1972)

[6] P. Lazzarin, R. Tovo, Int. J. Fract. 78, 3 (1996)

[7] A. Seweryn, A. Lucaszewicz, Eng. Fract. Mech. 69, 487 (2002)

[8] F.J. Gómez, M. Elices, A. Valiente, Fatigue Fract. Eng. Mater. Struct. 23, 795 (2000)

[9] F.J. Gómez, M. Elices, Eng. Fract. Mech. 70, 1913 (2003)

[10] F.J. Gómez, M. Elices, Int. J. Fract. 123, 163 (2003)

[11] F.J. Gómez, M. Elices, Int. J. Fract. 127, 239 (2004)

[12] P. Lazzarin, F. Berto, Int. J. Fract. 135, 161 (2005)

[13] F. Berto, P. Lazzarin, Theor. Appl. Fract. Mech. 52, 183 (2009)

[14] P. Lazzarin, F. Berto, M. Elices, J. Gomez, Fatigue Fract. Eng. Mater. Struct. 32, 671 (2009)

[15] F. Berto, P. Lazzarin, J. Yates, Fatigue Fract. Eng. Mater. Struct. 34, 921 (2011)

[16] D. Radaj, F. Berto, P. Lazzarin, Eng. Fract. Mech. 76, 1109 (2009)

[17] D. Radaj, P. Lazzarin, F. Berto, Int. J. Fatigue 31, 1490 (2009)

[18] F. Berto, P. Lazzarin, Mater. Sci. Eng. R 75, 1 (2014)

[19] F. Berto, P. Lazzarin, F.J. Gómez, M. Elices, Int. J. Fract. 148, 415 (2007)

[20] F.J. Gómez, M. Elices, F. Berto, P. Lazzarin, Int. J. Fract. 145, 29 (2007)

[21] K. Taghizadeh, F. Berto, E. Barati, Theor. Appl. Fract. Mech. 59, 21 (2012)

[22] M.R. Ayatollahi, F. Berto, P. Lazzarin, Carbon 49, 2465 (2011)

[23] P. Lazzarin, F. Berto, M.R. Ayatollahi, Fatigue Fract. Eng. Mater. Struct. 36, 942 (2013) 
[24] F. Berto, P. Lazzarin, C. Marangon, Mater. Des. 41, 421 (2012)

[25] S. Harding, A. Kotousov, P. Lazzarin, F. Berto, Int. J. Fract. 164, 1 (2010)

[26] A. Kotousov, P. Lazzarin, F. Berto, S. Harding, Eng. Fract. Mech. 77, 1665 (2010)

[27] F. Berto, P. Lazzarin, A. Kotousov, L.P. Pook, Fatigue Fract. Eng. Mater. Struct. 35, 538 (2012)

[28] P. Lazzarin, F. Berto, M. Zappalorto, Int. J. Fatigue 32, 1559 (2010)

[29] F. Berto, P. Lazzarin, Sci. China Phys. Mech. Astron. 57, 30 (2014)

[30] J. Aghazadeh Mohandesi, M.H. Shahossinie, Metall. Mater. Trans. A 36, 3471 (2005)

[31] J. Aghazadeh Mohandesi, M.H. Shahossinie, R. Parastar Namin, Metall. Mater. Trans. A 37, 2125 (2006)
[32] A. Nazari, J. Aghazadeh Mohandesi, S. Tavareh, Comput. Mater. Sci. 50, 1781 (2011)

[33] A. Nazari, Comput. Mater. Sci. 5, 3238 (2011)

[34] A. Nazari, J. Aghazadeh Mohandesi, S.H. Riahi, J. Mater. Sci. Technol. 27, 443 (2011)

[35] A. Nazari, J. Aghazadeh Mohandesi, S.H. Riahi, Int. J. Damage Mech. 20, 811 (2011)

[36] M. Abolghasemzadeh, H. Samareh Salavati Pour, F. Berto, Y. Alizadeh, Mater. Sci. Eng. A 534, 329 (2012)

[37] H. Samareh Salavati Pour, F. Berto, Y. Alizadeh, Acta Metall. Sin. (Engl. Lett.) 26, 232 (2013)

[38] E. Barati, Y. Alizadeh, J. Aghazadeh, Mohandesi. Eng. Fract. Mech. 77, 3341 (2010)

[39] ASTM E1820, Vol. 03.01, (2001)

[40] Z. Yosibash, A. Bussiba, I. Gilad, Int. J. Fract. 125, 307 (2004) 